\title{
RESEARCHES OF DIGITAL DESIGN SYSTEM OF RICE CULTIVATION BASED ON WEB AND SIMULATION MODELS
}

\author{
Hongxin Cao ${ }^{1, *}$, Zhiqing Jin ${ }^{1}$, Yuwang Yang ${ }^{2}$, Chunlin Shi ${ }^{1}$, Daokuo $\mathrm{Ge}^{1}$, \\ Xiufang Wei ${ }^{1}$ \\ ${ }^{1}$ Institute of Agricultural Resources and Environment Research/Engineering Research Center \\ for Digital Agriculture, Jiangsu Academy of Agricultural Sciences, Nanjing 210014, Jiangsu, \\ China \\ 2 School of Computer Sciences, Nanjing University of Sciences \& Technology, Nanjing \\ 210014, Jiangsu, China \\ * Corresponding author, Address: Institute of Agricultural Resources and Environment \\ Research/Engineering Research Center for Digital Agriculture, Jiangsu Academy of \\ Agricultural Sciences, 50 Zhongling Street, Nanjing 210014, Jiangsu, China, Tel: +86-25- \\ 84390125, Fax:+86-25-84390248, Email: caohongxin@hotmail.com
}

Abstract: In order to integrate web with crop growth simulation and decision-making support system, the field experiment of different basal levels was carried out in experiment area of Jiangsu Academy of Agricultural Sciences in 2005 adopting 4 cultivars such as "Wuyungeng 7", "Yangdao 6", "Yueyou 948" and "Nangeng 41", which mainly were used in collecting cultivar parameters and updating database of them. The database of rice cultivars, soil and weather data were developed using SQL Server 2000. The pages of digital design system of rice cultivation based on web and simulation model (DDSRCBWSM) were designed using Visual Studio.Net, which included register, the main page, cultivar parameter management, site data management, parameter adjustment, decision making for rice cultivation, and so on. The DDSRCBWSM accorded with TCP/IP agreements, which could be installed and run in server (IIS5.0), and be browsed on internet, it inherited mechanism, universal adaptability and utility of rice cultivation simulationoptimization-decision making system (RCSODS), combined web techniques with research of rice growth models, set up web system of RCSODS, made agricultural technicians of main rice production area of china gain pre-sowing optimization cases and rice management suggestion of the current year with dynamic, goal and digital characteristic in accordance with soil, cultivar and weather conditions online, and to fulfill technical direction through many kind manner such as paper, internet, email, television, wall newspaper, and so on, eventually.

Cao, H., Jin, Z., Yang, Y., Shi, C., Ge, D. and Wei, X., 2008, in IFIP International Federation for Information Processing, Volume 259; Computer and Computing Technologies in Agriculture, Vol. 2; Daoliang Li; (Boston: Springer), pp. 1077-1086. 
Keywords: Web, Simulation model, Rice cultivation, Decision-making support system, Digital design

\section{INTRODUCTION}

China is the largest country of rice production and consumption in the world. Rice accounted for more than $50 \%$ of commodity food in China, its plant area was about from $28,000,000$ to $31,000,000$ ha and the total yield was from $120,000,000$ to $180,000,000$ ton in the normal year, which was $30 \%$ of total plant area and $43.6 \%$ of total yield of food crops in China, respectively. The matching of both good cultivars and its optimum cultivation techniques was an important scientific guarantee of steady increase for rice production in China; the Rice Cultivation SimulationOptimization-Decision Making System (RCSODS) (Gao and Jin et al., 1992) provided an available way for the matching. However, RCSODS was still not integrating with web, and its extensive application was limited to some extent.

There were reports inland and overseas for studies on integrating database (DB), agricultural expert system (AES), decision-making support system (DSS), agricultural model, and so on with web. Many researchers integrated fertilization models, groundwater models, soil and water quality models, DSS or DB with web, respectively (Comis, 1999; Shaffer, 2002; McCown, 2002; Winston, 2002; Gunn et al., 2002; Bostick et al., 2004; Miller et al., 2004). Researches of integrating DB, AES, soil eroding models, DSS or GIS with web had also been reported (Shi et al., 1999; Yu, 2000; Gao et al., 2000; Liu et al., 2001; Yang et al., 2002; Liao et al., 2002; Li et al., 2003; Wang et al., 2003; Chu, 2003; Chen et al., 2003; Wang et al., 2004). However, the studies of integrating crop growth models and agricultural DSS with web were not reported in literature inland and overseas.

The objective of this research were integrating DB of rice cultivars, soil and weather data, rice growth models, rice optimization models with web platform, implementing internet running of rice growth models and optimization models based on RCSODS.

\section{MATERIALS AND METHODS}

\subsection{Materials}

In order to update cultivar parameter DB, WUYUNGENG 7, YANGDAO 6, YUEYOU948, and NANGENG 41 were adopted as experiment materials. 


\subsection{Methods}

\subsubsection{Field experiment}

The trail was conducted in 2005 in experiment area of Jiangsu Academy of Agricultural Sciences, Nanjing, China, as split-plot arrangements (main plots were basals including 2 levels (fertilizer and no fertilizer (CK), thereinto, fertilizer included basals of nitrogen rate at $75 \mathrm{~kg} \cdot \mathrm{ha}^{-1}, \mathrm{P}_{2} \mathrm{O}_{5}$ at 120 $\mathrm{kg} \cdot \mathrm{ha}^{-1}$, and $\mathrm{K}_{2} \mathrm{O}$ at $45 \mathrm{~kg} \cdot \mathrm{ha}^{-1}$, nitrogen rate during tiller period at $60 \mathrm{~kg} \cdot \mathrm{ha}^{-1}$, and nitrogen rate during ear and grain period at $45 \mathrm{~kg} \cdot \mathrm{ha}^{-1}$ ), sub-plots were cultivars with 4 levels) with 8 treatments, 3 replications, and 24 plots, each plot size was $(10 \times 3.029) \mathrm{m}^{2}$, and there were 13 rows per plot.

The former crop of the experiment field was fallow, its soil fertility was at middling-crackajack, the soil from the topsoil $(0-40 \mathrm{~cm}$ depth) contained soil organic content at $19.8 \mathrm{~g}^{\circ \mathrm{kg}^{-1}}$, alkali soluble nitrogen at $138.6 \mathrm{mg} \bullet \mathrm{kg}^{-1}$, available phosphorus at $19.9 \mathrm{mg} \bullet \mathrm{kg}^{-1}$, available potassium at $141.9 \mathrm{mg} \bullet \mathrm{kg}^{-1}$, and $\mathrm{pH}$ at 6.51 . The deep plowing in the land preparation was conducted on May 18, planting date was on May 15, the basals was applied on Jun 15, transplant was conducted on Jun 16 , urea $6.5 \mathrm{~kg}$ (nitrogen rate $60 \mathrm{~kg} \cdot \mathrm{ha}^{-1}$ ) was applied on Jun 21 and $4.65 \mathrm{~kg}$ (nitrogen rate $45 \mathrm{~kg} \cdot \mathrm{ha}^{-1}$ ) on Aug. 17, the other field managements were the same as general rice field.

\subsubsection{Data to be collected}

They included phenology recordation, tagging and recording leaf age, investigating plant density, yield, and yield components. The shoot and tillering dynamic were investigated 1 time every 5 days, beginning from tillering date, 2 rows $30 \mathrm{~cm}$ length each plot. LAI, the dry matter, population spectrum feature, plant nitrogen content and phosphorus content also were determined at rice main phenology period such as transplanting date, reviving date, tillering date, elongation date, heading date, anthesis, filling date, and mature date, sampling by the conventional means, thereinto, population spectrum feature was determined using EXOTECH100BX spectrum radiometer. Plant analysis (conventional items) at mature was conducted in laboratory. 


\section{DESIGN OF STRUCTURE AND FUNCTIONS OF THE SYSTEM}

\subsection{Design of DB}

The DB of rice cultivars, soil, and weather data were developed by SQLServer2000. The rice cultivar DB included model parameters (rice phenology, leaf age, photosynthesis, yielding components, internode numbers, tillering rate, leaf area per plant, optimal season, and temperature index at all heading date), genetic characteristics of cultivars and knowledge DB of controlling pest and weed. The soil parameter DB involved soil types, texture, organic matter, total nitrogen, available phosphorus, available potassium, $\mathrm{pH}$, ratio of volume to weight, saturation water content, field hold water content, and wilting point etc., the weather DB dealt with monthly or daily average temperature, maximum temperature, minimum temperature, sunlight time, precipitation, and raining days etc.

\subsection{Design of The System's Functions}

The system's functions mainly involved management of cultivar DB and site DB, cultivar parameter adjustment, and rice cultivation decision-making (see Fig. 1). The DB, knowledge DB and model class libraries, and functional modules accorded with TCP/IP agreements, which could be installed and run in server (IIS5.0), and be run on any browser of internet.

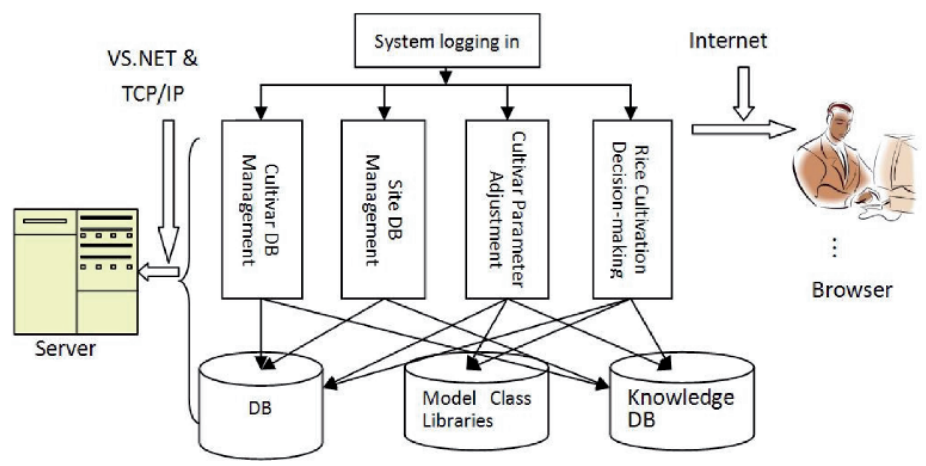

Fig. 1. The function frame chart of the DDSRCBWSM 


\subsubsection{DB management}

In order to fulfill appending, deleting and modifying of data online, the application program of ASP.NET Web in VS.NET needed to be run when calling cultivar and knowledge DB, and site DB of SQL Server, and weather simulator.

\subsubsection{Cultivar parameter adjustment}

In order to fulfill adjusting of cultivar parameters online, the application program of ASP.NET Web in VS.NET needed to be run when calling cultivar and knowledge DB of SQL Server, and model class libraries (rice growth models and optimum models).

\subsubsection{Rice cultivation decision-making}

In order to fulfill the normal and the current year decision-making of rice cultivation, show curves of the optimum LAI, shoot and tillering dynamic for rice, and build tables of cultivation case online, the application program of ASP.NET Web in VS.NET needed to be run when calling cultivar and knowledge DB of SQL Server, and model class libraries (rice growth models and optimum models).

\subsection{Design of Web Pages of The System}

They included enter page (Fig. 2), the main interface page of the system (Fig. 3), the cultivar DB management page (Fig. 4), the site and weather DB management page (Fig. 5), the parameter adjustment page (rice phenology, leaf age, photosynthesis, yielding components, node numbers and tillering rate, leaf area per plant, optimal season, and temperature index at all heading date) (Fig. 6) and the rice cultivation decision-making page (Fig. 7).

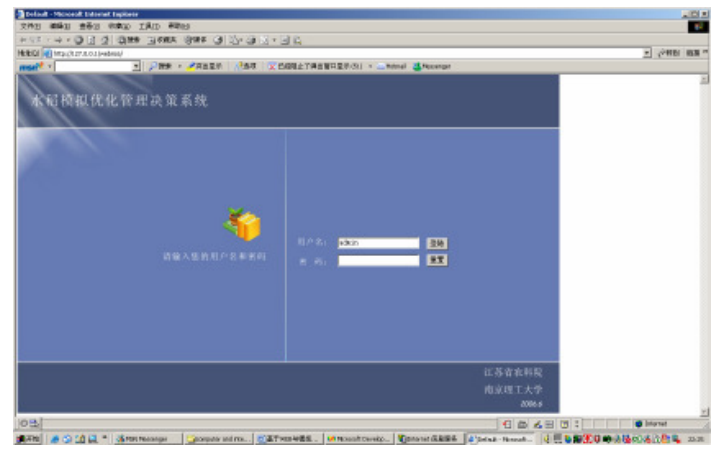

Fig. 2. The enter page 


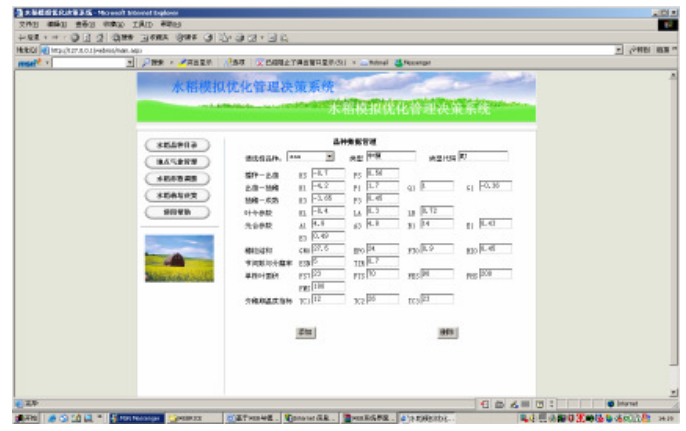

Fig. 3. The main interface page of the system

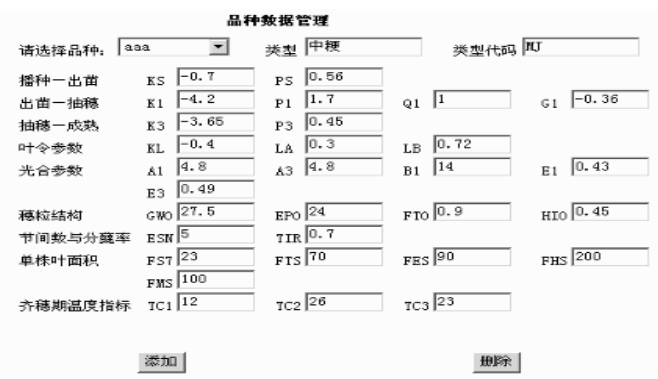

Fig. 4. The cultivar DB management page

\begin{tabular}{|c|c|c|c|c|c|c|c|}
\hline \multicolumn{8}{|c|}{ 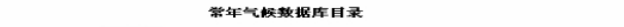 } \\
\hline \multirow[t]{2}{*}{ 诘选操地点。 } & \multicolumn{2}{|c|}{ 福叶二 } & \multicolumn{3}{|c|}{ 纬度, 26.01} & \multirow[b]{2}{*}{ 月雨晊 } & \multirow[b]{2}{*}{ 月然时 } \\
\hline & 月涂 & 西色 & 最高要 & 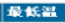 & E国时时 & & \\
\hline 编辌 & 1 & 11.5 & 15.8 & 8.7 & 96.0 & 52.1 & 10.4 \\
\hline 编轵 & 2 & 11.8 & 15.9 & 9.1 & 73.1 & 83.8 & 14.3 \\
\hline 编转 & 3 & 14. 1 & 18.6 & 11.3 & 81.6 & 144.2 & 16.9 \\
\hline 编转 & 4 & 18.8 & 23.5 & 15.5 & 109.7 & 143.4 & 16.8 \\
\hline 编转 & 5 & 23.2 & 27.5 & 20.0 & 123.4 & 177.5 & 18.3 \\
\hline 掄转 & 6 & 26.7 & 30.8 & 23.6 & 139.9 & 185.1 & 16.5 \\
\hline 漏转 & 7 & 29.6 & 34.3 & 26.0 & 222.9 & 98.4 & 10.4 \\
\hline 漏轵 & 8 & 29.1 & 33.8 & 25.7 & 191.6 & 177.0 & 12.4 \\
\hline 编䢂 & 9 & 26.4 & 30.6 & 23.4 & 141.7 & 180.1 & 12.0 \\
\hline 编模 & 10 & 22.7 & 27.0 & 19.5 & 141.6 & 32.2 & 6.8 \\
\hline 编转 & 11 & 18.7 & 23.0 & 15.5 & 116.6 & 36.5 & 7.3 \\
\hline 编较 & 12 & 13. 7 & 18.3 & 10.5 & 117.3 & 30.4 & 7.9 \\
\hline & 深加地 & 点 & & 地点 & 专君年 & 担数据 & \\
\hline
\end{tabular}

Fig. 5. The site and weather DB management page

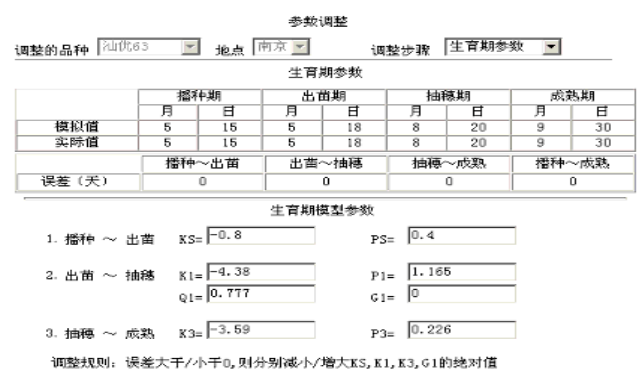

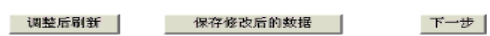

Fig. 6. The parameter adjustment page 


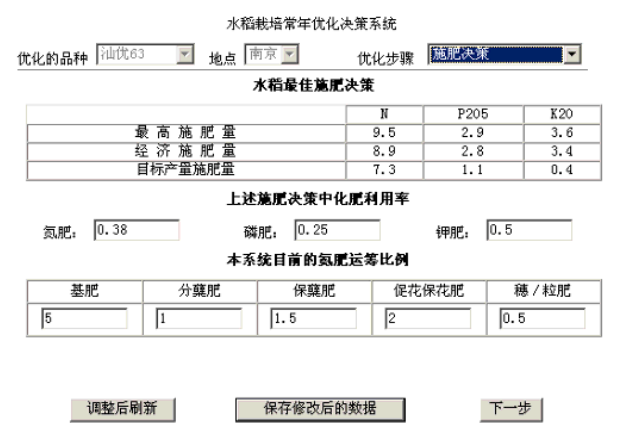

Fig. 7. The rice cultivation decision-making page

\subsection{The Run Environment of The System}

It needed to install WIN2000Server or upward operating system, dot NET framework, SQLServer2000 or upward DB system, EXCEL5.0 or upward, and IE6.0 or upward software in server, WIN98 or upward operating system, EXCEL5.0 or upward, and IE6.0 or upward software in client.

\subsection{The System Application Cases}

The system may establish and down the optimum sheet of pre-planting for rice online by browser through selecting weather data in the normal year in Nanjing, cultivar data of XIANYOU 63, and soil nutrition etc., adjusting cultivar parameter of XIANYOU 63, and conducting the optimum decisionmaking sheet of pre-plant (Fig. 8), which included the rice growth and development period, the optimum population dynamic, and the optimum fertilizer rate, the assign of nitrogen, and the control of pest and weed, and so on, with strong technique and maneuverability.

\section{CONCLUSIONS AND DISCUSSIONS}

The DDSRCBWSM implemented integration of the rice growth models, the rice optimum models, and DB with web, developed internet platform of rice simulation-optimization-decision making, and provided basis for application of rice growth models online.

The DDSRCBWSM inherited mechanism, universal adaptability and utility of RCSODS, combined web techniques with research of rice growth models, can establish pre-sowing optimization cases and rice management suggestion of the current year with dynamic, goal and digital characteristic 


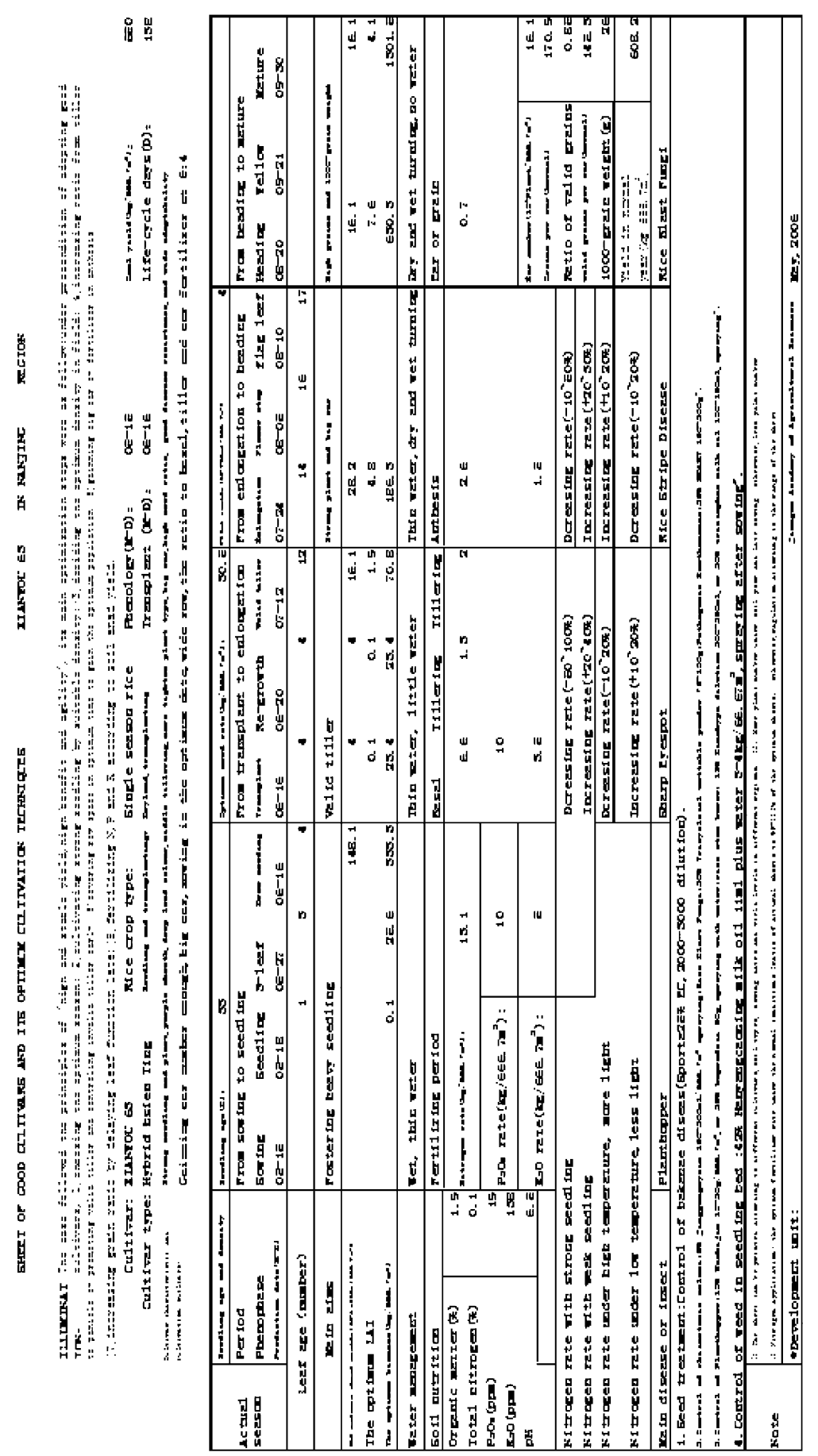

Fig. 8. The pre-plant optimum cases for XIANYOU 63 planted in Nanjing 
in accordance with soil, cultivar and weather conditions online, and to fulfill technical direction through many kind manner such as paper, internet, email, television, wall newspaper, and so on.

The DDSRCBWSM also provided internet platform combining with expert knowledge, images, video, and field task record and traceable management etc., can help to direct rice standardization production.

At present, the DDSRCBWSM has not integrated with GIS, however, the realization of region distributing and large-scale direction functions will require supports of GIS, it will need to be strengthened on this aspect.

\section{REFERENCES}

Bostick M, Koo J, Walen V K, Jones J, Hoogenboom G. A web-based data exchange system for crop model applications. Agronomy Journal, 2004, 96(3):853-836

Chen S H, Mao D M, Xu Y M. Development of soil nutrition regional management system in Xinjiang Uigur Autonomous WEBGIS-based. Modernization Agriculture, 2003, (11):2729 (in Chinese)

Chu J X. Design and Development of the Web Based Forest Fire Forecast System. FOREST RESOURCES MANAGEMENT, 2003, (5):58-60 (in Chinese)

Comis D. Model takes the guesswork out of fertilizing, Agricultural Research,1999, 47(10): 15

Gao D M, Yang P H. Implement of web database in internet corn expert system. Journal of Taiyuan University of Sciences \& Technology, 2000, 31(5):477-480 (in Chinese)

Gao L Z, Jin Z Q, Huang Y, Li B B. Rice Cultivational Simulation-optimization-decision Making System. Beijing: Chinese Agri Sci \& Tech Press, 1992, pp. 21-40 (in Chinese)

Gunn R L, Mohtar R H, Engel B A. World-Wide-WEB-based soil and water quality modeling in undergraduate education, Journal of Natural Resources and Life Sciences Education, 2002, 31:141-147

Li X, Yang B Z, Guo T C, Zhao C J, Chen L P. Researches of field crop management geographical information system based on integration of WebGIS and ES. Journal of North China Agronomy, 2003, 18(2):106-109 (in Chinese)

Liao G P, Li A P, Wu Q Y, Guan C Y. Knowledge Representation of Prescribed Fertilization in Web-Based Expert System of Rapeseed (B. napus) Production. Journal of Hunan Agricultural University (Natural Sciences), 2002, 28(5):378-382 (in Chinese)

Liu H T, Qin Q M. Researches and application of soil eroding model WEBGIS-based. Journal of Water and soil Preserve, 2001, 15(3):52-55 (in Chinese)

McCown R L. Changing systems for supporting farmers' decisions: problems, paradigms, and prospects Agricultural Systems, 2002,74(1):179-220

Miller R C, Guertin D P, Heilman P. Information technology in watershed management decision making, Journal of the American Water Resources Association, 2004, 40(2): 347-357

Shaffer M J. Nitrogen modeling for soil management, Journal of Soil and Water Conservation, 2002, 57(6):417-425

Shi J P, Lu R K, Wang D J. Design and establishment of databases for fertilizing decisionmaking support WEB-based. Soil, 1999, (6):299-316 (in Chinese) 
Wang L S, Qi G Q, Fan Y C. Design and development based on net of agricultural decision consulting system. Agricultural Mechanization Research, 2003, (2):136-137 (in Chinese)

Wang S L, Zhang L W, Liu G S, Wang J L. Researches of agricultural weather information service technology online. Chinese Agricultural Meteorology, 2004, 25(1):1-4 (in Chinese)

Winston R B. Ground water modeling software on the Internet, Ground Water, 2002, 40(4):335-336

Yang B Z, Zhao C J, Li A P, Wu Q Y, Sun X, Wu H R. Researches and application of agricultural expert system platform (PAID) based on WEB and components. High Technology Newsletter, 2002, (3):5-9 (in Chinese)

Yu G H. Farm information services system FIIS based on the web. Computer \& Agriculture, 2000, (9):13-17 (in Chinese) 